\title{
Cancer: it's time to change the sign
}

Previously published at www.cmaj.ca

$\mathrm{O}$ ver the past 10 years, the hospitals where I work have undergone major renovations and facelifts. Indeed, they are scarcely recognizable anymore except for one thing: the sign in the main entrance, telling people to donate money or "join the fight" to cure cancer. I think it's time to change the sign.

It's not that I don't like the idea of curing cancer. That would be great. It's just a little unrealistic. Over the past four decades, we have spent billions of dollars studying surgical techniques, chemotherapies and immunotherapies. Very few have shown benefit. Despite notable successes in treating rare cancers, overall age-adjusted cancer mortality actually increased until the mid1990s, ${ }^{1}$ and has only slightly decreased overall since $1950{ }^{2}$ This stands in stark contrast to improvements in North America's other major cause of mortality, coronary artery disease, which has seen an overall reduction in age-adjusted mortality of $68 \%$ over the same time period. ${ }^{3}$ In 1997, one researcher famously commented in the New England Journal of Medicine that 50 years of "effort focused largely on improving [cancer] treatment must be judged a qualified failure," and cautioned readers to take a "skeptical view of the ... assumption that marvelous new treatments ... are just waiting to be discovered."'

Of course, that doesn't mean that we will never cure cancer, or that we should stop trying. But maybe we should stop writing slogans such as: "When the next discovery means a cure" and "Conquer cancer in our lifetime." These statements imply that a universal cure for cancer is both likely and imminent. In fact, "cancer" is really a diverse group of diseases with different pathophysiologies. We are no more likely to find a single "cure" for all cancers than we are to find a single cure for all infections. And while we may find many effective cancer treatments in the next 20 years, we are unlikely to find any cures in the lifetime of a person with terminal cancer. These simplistic slogans are misleading. Why can't we just ask the public to support "cancer research"?

Patients with cancer come to us for treatment and they trust us to give them good advice and reliable information. Although the public's knowledge about cancer is improving, many people hold falsely optimistic beliefs about cancer survival. ${ }^{4}$ Many also demonstrate an optimism bias - an irrational belief that their own survival chances are better than those of another person with exactly the same disease. ${ }^{5}$

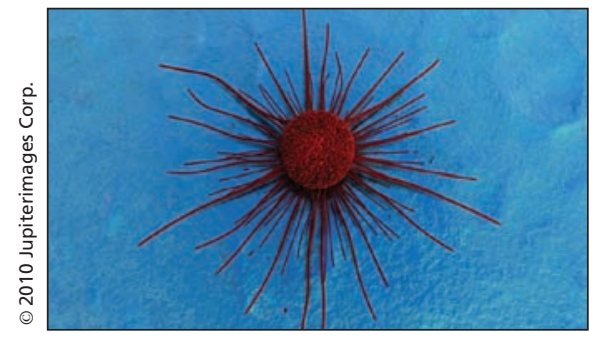

Where does this optimism come from? In part, from hospitals and research organizations which tell patients that new treatments and cures are imminent. A little optimism may be beneficial: it encourages patients to seek out screening and early diagnosis, ${ }^{4}$ and increases the likelihood that patients will adhere to treatment regimens that may be beneficial. On the other hand, false optimism may lead patients to request (even insist upon) nonbeneficial treatments, and endure unpleasant and life-threatening side effects for no reason. Unrealistic optimism is also a major barrier to effective palliative and end-of-life care, which is a key component of cancer treatment.

Ultimately, many patients are surprised when their doctor tells them that their cancer is not curable and that the treatment options are limited. After all, the posters in the waiting room assured them that cancer can (and will) be cured. Who can blame them for being surprised? Why are we surprised when they make "unrealistic" treatment demands?

Other posters feature military-style slogans, asking patients and the public to "conquer" or "join the fight" against cancer. A military analogy is inspiring, because people like to work toward a victory over an "enemy." But cancer is not an enemy. It is a disease, like heart disease or urinary tract infection. Patients are not soldiers, and doctors are not generals. Cancer does not have a geopolitical agenda or an army; it is not even intelligent.

The military analogy is ultimately harmful, because it creates a culture of victory. Patients are expected (and volunteer) to "fight" by undergoing treatments that can have horrendous side effects. If they respond and the cancer remits, they are called "survivors" (a term of victory). On the other hand, if the cancer relapses or progresses and further treatments are no longer effective or tolerable, many patients find it hard to make the transition to palliative care. It sounds too much like defeat.

Hospitals should continue to ask for donations to support cancer research, and I hope that someone eventually finds "a cure." But we need to tone down the military slogans, and recognize that there is a big difference between hoping for a cure and telling the public that a cure is imminent. We are harming our patients when we present cancer research in such terms. It's time to change the sign.

\section{James Downar MDCM MHSc}

Palliative care and intensive care physician

Toronto General Hospital

Toronto, Ont.

\section{REFERENCES}

1. Bailar JC, Gornik HL. Cancer undefeated. N Engl J Med 1997;336:1569-74.

2. Kort EJ, Paneth N, Woude GFV. The decline in US cancer mortality in people born since 1925 . Cancer Res 2009;69:6500-5.

3. National Heart Lung and Blood Institute: National Institutes of Health. NHLBI Factbook, fiscal yea 2008. Washington (DC): US Department of Health and Human Services; 2008.

4. Donovan RJ, Carter OBJ, Byrne MJ. People's perceptions of cancer survivability: implications for oncologists. Lancet Oncol 2006;7:668-75.

5. Clarke VA, Lovegrove H, Williams A, et al. Unrealistic optimism and the Health Belief Model. $J$ Behav Med 2000;23:367-76. 